\begin{abstract}
Reference Librarian: Required:
Smiles when patrons approach. Speaks well. Listens better. Still smiles while answering the 10,000th bathroom-location question. Writes most sentences in the active voice. Shows instead of tells. Does not make fun of patrons. On handouts uses big type and few words. Happily works nights and weekends. Goes out to faculty offices on own initiative. Between patron questions, studies reference sources that he/she should have used to answer the last question but didn't. Learns spelling and meaning of important words in area of assigned responsibility. The ideal candidate is bored by assigning blame and does not find comfort in excusing bad service by cit-
\end{abstract}

ing policy. MLS. Desired-. Gets book orders in before the deadline. Does not have to be drafted but volunteers to teach user education sessions. Remembers to remove uneaten lunches from staff refrigerator.

This is the person I want for reference. If I hire someone who claims to be able to search BIOSIS but can't, I can teach that skill. If I hire someone who claims to love working nights but blows up when actually asked to do so, I can't teach flexibility or professional commitment. At best, $\mathrm{T}$ can work with the employee to develop responses where he or she has ability, but no experience. Because nobody would approve ads that clearly state desired qualities in a detailed manner, we need those short phrases to cover in a legal and af-

\title{
Scott DiMarco responds
}

Shortly after my article was published in the June 2000 issue, I received immediate positive feedback from many esteemed colleagues. I thank them. I thank the writer of this essay for agreeing with many points and welcome her comments on the few differences of opinion. I am sure we all agree that when it comes to the recruitment process, sculpting a job advertisement is easier said than done.

I sympathize with the writer and her frustration about the process and would like to address just a few of the points mentioned. A common mistake is giving the job advertisement far too much credit, as it is just one part of a detailed process.

First, while we all feel for the unqualified job seeker trying to catch a break, it doesn't mean we can include an unqualified applicant in our search. The time spent on such applications is wasted for both parties. Also, certain standards and minimums must be enforced. For example, degree requirements must be adhered to even if they seem "ego-threatening" to many.
The essay perpetuates the myth that one isn't responsible for his or her actions in our society. Accepting late applications because the applicant has just started their search is irresponsible. Try telling government agencies or foundations that your grant application should be considered late because you just heard about it.

How is this fair to those who followed the rules? Lawsuits and liability are far too common for us not to protect ourselves.

A vague position description will only increase frustration within the search process. I, for one, would much rather be presented with as many of the details concerning the position as possible. How else could anyone make an educated decision?

I welcome feedback or comments from colleagues in regards to bettering the search process. After all, we are all in this together.-Scoff $R$. DiMarco, Herkimer County Community College, dimarcosr@hccc.suny.edu 
fordable manner many interpersonal and personal specifics. I was sorry to see that DiMarco did not provide us with an ideal advertisement incorporating his advice.

\section{Some good advice}

$\mathrm{He}$ does get some points right. His plea for job-specific job descriptions should be heeded. Job descriptions written by committee members who work in similar jobs or in the same unit stand a better chance of pulling in the best from the current pool of available workers.

A common variation is to expect more subject background from humanities or social sciences librarians than from science librarians simply because the market can bear it. Few libraries can afford someone with a master's or doctoral degree in physics, chemistry, or engineering. If a library administrative office is surprised by something in a proposed job description, it should not assume ignorance on the part of the authors. Automatically editing out unique requirements is asking for frustration and failure.

DiMarco is right about specifying salary range. With today's changing words for people in charge or, more likely, not in charge, but responsible anyway, publicizing the salary range may be the most honest indicator of the true authority of the position. A few people who are currently making more money may save themselves the effort of applying, although not necessarily.

In other cases, an administrator may feel the need to save interview costs by pointing out via the telephone that the published salary limitations are real.

DiMarco makes important points about unique job descriptions and salary requirements. He is right that the phrases are vague. But the pressures of our environment cause most of what he dislikes, and until our employment and legal environments change, I urge you to save yourselves. Keep those vague phrases coming.

\section{Notes}

1. Scott R. DiMarco, "I Know That's What It Said, But It's Not What We Want: The Difficulty of Really Describing a Job," $C \& R L$ News 61 (June 2000): 503-5.

2. Ibid., 503.

3. Ibid., 504. -

\section{*ChoiceReviews.online}

\section{It's more than just a database of reviews!}

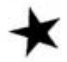

$\star$ Internet access to all CHOICE reviews since Sept. 1988 -some 80,000 reviews at your fingertips

$\star$ E-mail alerts of new reviews, based on your profile

$\star$ Create and store groups of reviews by subject, fund code, department, etc. You can even e-mail reviews to others!

$\star$ SUBSCRIBE NOW for $\$ 395$ ! Annual subscription includes personalized password access for up to 20 users and all corresponding print issues of the magazine.

\section{* Sign up for a free trial today! * www.ChoiceReviews.org \\ Phone: (860)347-6933 x23 Fax: (860) 704-0465 \\ E-mail: choiceonline@ala-choice.org 100 Riverview Center, Middletown, CT 06457}




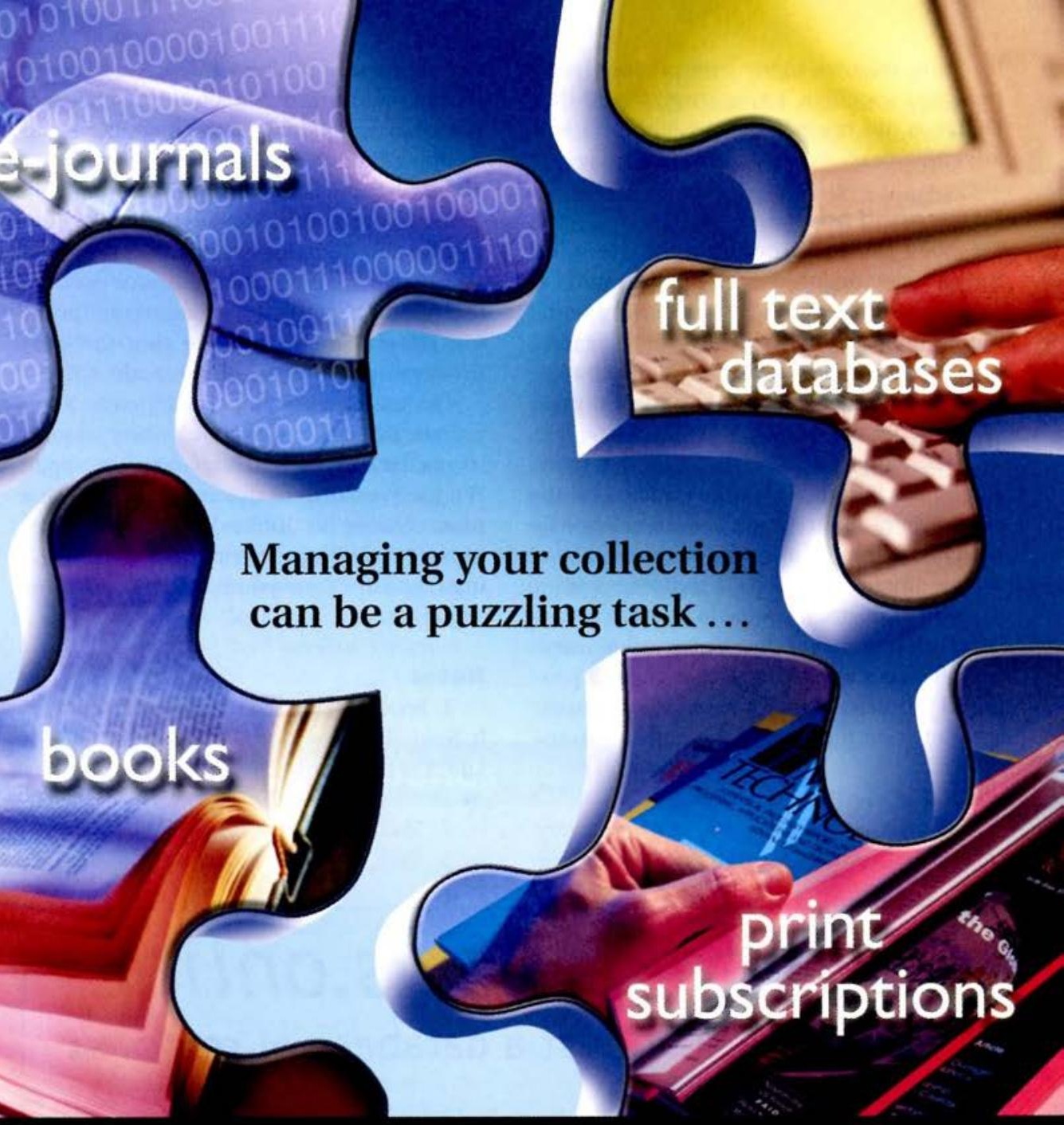

\section{EBSCO is bringing the pieces together.}

- Subscription management solutions for organizations worldwide from 32 offices in 21 countries.

- Full text databases with comprehensive collections of academic, biomedical, business and general interest titles through the EBSCOhost ${ }^{\circ}$ interface, and EBSCO SmartLink ${ }^{\mathrm{TM}}$ from article citations to full text.
For more information, visit us online at www.ebsco.com.

- Electronic journals via EBSCO Online ${ }^{\circ}$, a sophisticated interface for accessing and searching online journals, now with alerting capabilities and pay-per-view article purchasing.

- Online book ordering through EBSCO Book Services, coupling a simple interface with invoicing and reporting options that make managing book procurement easier.

EBSCO Information Services ... bringing together the pieces of your information collection.

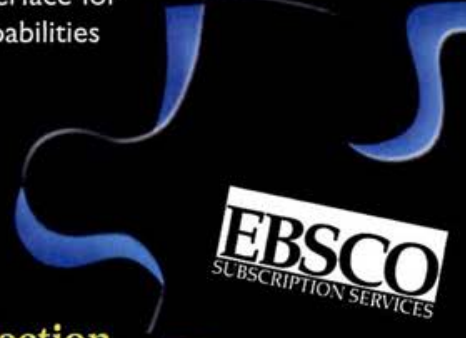

